\title{
Supporting transition: an analysis of the experience and performance of widening access students on their undergraduate degree programmes
}

Jason Annetts

Hazel Work

Andrea Cameron

Amy Miller

Vilja Niitamo

Marnie Stirling

Annetts, J., Work, H., Cameron, A.J., Miller, A., Niitamo, V. \& Stirling, M. (2019) 'Supporting transition: an analysis of the experience and performance of widening access students on their undergraduate degree programmes', Widening Participation and Lifelong Learning, 21(3), pp. 132-150.

(C) the authors, 2019. The definitive, peer reviewed and edited version of this article is published in Widening Participation and Lifelong Learning,

DOI: https://doi.org/10.5456/WPLL.21.3.132 


\title{
Supporting Transition: An analysis of the experience and performance of widening access students on their undergraduate degree programmes \\ Jason Annetts, Hazel Work, Andrea Cameron, Amy Miller, Vilja \\ Niitamo, Marnie Stirling, Abertay University \\ Email: j.annetts@abertay.ac.uk
}

\begin{abstract}
The paper examines the experience and performance of Abertay undergraduate students who entered higher education through the University's Access to Higher Education programme, AHEAD. The research is largely based on a qualitative analysis of two focus groups and nine indepth, semi-structured interviews with former AHEAD students. A statistical analysis of the performance of all AHEAD students on their chosen undergraduate degrees between 2012-13 and 2016-17 was also conducted. The paper demonstrates that AHEAD is an effective alternative route to higher education and argues that university-based access courses may be better in preparing these students for the culture and rigours of university life.
\end{abstract}

Key words AHEAD, Widening Participation, Higher Education, Nontraditional Students

\section{Introduction}

Despite the Scottish Government's commitment to widening access, research continues to demonstrate that individuals from disadvantaged backgrounds are less likely to go to university. Those that do pursue further education are also more likely to be diverted into lower prestige college courses. While socio-economic disadvantage remains the primary barrier for entry into higher education, access is also affected by other markers of disadvantage such as care experienced individuals, people with physical or sensory disabilities, those with poor physical or mental health and those from minority ethnic groups (Department for Business, Innovation \& Skills 2014, Scottish Government 2015). These barriers are often reinforced by the complex processes of social reproduction (Bourdieu 2010; Leese 2010; Bowl 2001; Marshall 2016) that ensure that many feel that higher education is "not for the likes of us".

The Scottish Credit and Qualification Framework (SCQF) is designed to promote life-long learning and to provide a variety of entry routes into a 
Scottish four-year undergraduate degree programme. Predominantly, entry is through the successful completion of Highers (SCQF level 6) at either high school or college into the first year of a four-year degree (SCQF level 7). However, there are a number of other routes which enable advance standing into second year (level 8) such as A levels, Advanced Highers and Higher National Certificates (HNC); third year (level 9), predominantly Higher National Diploma (HND); and, relatively rarely fourth year (level 10), for example, those who completed a college ordinary degree. The system is designed to promote flexibility and to ensure that students are rewarded for their prior learning.

For students without the requisite qualifications there are also a range of Access to Higher Education courses of which, in Scotland, the SCQF level 6 Scottish Widening Access Programmes (SWAP) are the most important. SWAP courses are one-year full-time college-based programmes designed to provide to provide students without the requisite qualifications an entry route into higher education at a partner university. This Scottish widening access system, therefore, predominantly relies on college-based Access and Higher National courses (Weedon 2015; Gallacher 2017) and this can serve to accentuate rather than alleviate the social reproduction of disadvantage. While many Scottish universities now run summer schools, have schools' outreach programmes and increasingly deploy contextual offers to meet their funding council's outcome agreement targets, the bulk of non-traditional students continue to access higher education through the college sector.

This paper explores the impact of an alternative university-based widening access programme which Abertay University has run for the past 20 years and which was significantly redesigned in 2012. The Access to Higher Education Abertay Dundee (AHEAD) programme aimed to alleviate the impact of a poor educational history by offering non-traditional students without appropriate qualifications a means to access an Abertay degree. This programme aims to develop its students' study skills, increase their levels of confidence and socialise them into the culture and expectations of university study prior to their entry onto an undergraduate degree. For the widening access student there are range of benefits associated with completing the AHEAD programme, as it is free, part time, delivered in the evening and guarantees successful students a university place. In this way, AHEAD differs from almost all widening access courses in Scotland which tend to be fulltime day courses delivered within the college sector. SWAP is a vital part of Scotland's widening access landscape; however, recent studies have raised questions about the extent to which such programmes fully prepare these students for the culture of university study (Christie, Munro \& Wager 2005; Weedon 2015; Gallacher 2017). Prior findings suggest that one of the benefits of the AHEAD programme is that it is based in a university, developing its students' skillset but also providing what amounts to a year-long induction programme into university study, its culture, expectations and rules (Annetts, 
Cameron, Work, Miller, Niitamo \& Stirling, 2017). Furthermore, many of those involved in delivering the AHEAD programme are also involved in teaching the former AHEAD students on their degrees once they make the transition to undergraduate study. In this way the AHEAD programme embeds these students in the university's support network which further aids their transition into undergraduate study.

\section{Methodology}

Data collection involved: (1) a statistical analysis of the performance of former AHEAD students on their chosen undergraduate degrees between 2012-13 and 2016-17; (2) a qualitative analysis of two focus groups conducted by undergraduate student researchers; and (3) a small number of in-depth semi-structured interviews, conducted by the lead researchers, with former AHEAD students who had made the transition to an Abertay University degree programme.

This research was made possible by a small grant from the Abertay Teaching Learning Education Fund (ATLEF) which advocates for the use of student researchers.

The project was conducted in three phases between December 2016 and October 2017. During phase 1 three student researchers were recruited to conduct a wide-ranging literature search on access, transition and higher education and to organise and lead focus groups with former AHEAD students studying at higher education level. These student researchers received full training in conducting focus groups during this phase before they invited the former AHEAD students to take part in the research. Phase 2 was the data collection phase and involved two focus groups $(n=16)$ and 9 semistructured interviews with former AHEAD students. While three of the nine interviewees were male, the rest of the participants were women. In part, this reflects the greater number of women who both sign up for, and complete, the AHEAD programme. The interviews were designed to enable the researchers to explore in more depth some of the issues raised in the focus groups as well as recording interviewees' experience of the transition from the AHEAD programme to undergraduate study. Finally, Phase 3, the analysis phase, focus groups and interviews were fully transcribed and thematically analysed by the lead researchers, and a statistical analysis of former AHEAD students' degree performance was also completed and compared to the performance of all Abertay students in each year group.

\section{AHEAD Student Performance in HE}

More than two-thirds of AHEAD students were drawn from the local community, over $60 \%$ of the cohort were female, more than $25 \%$ came from the most deprived quintile of the Scottish population and $10 \%$ identified as BME (BME population for Dundee City is 6\% and much lower in the neighbouring local authorities (DCC, 2015)). Of the 144 students who 
enrolled between 2012 and 2016, half registered for Abertay degree programmes (range 41-63\%). A small level of attrition was observed with each ensuing stage of study (Figure 1). However, it should be noted that many still exited with a recognisable university qualification.

Figure 1: Patterns of progression from the AHEAD programme by year of enrolment

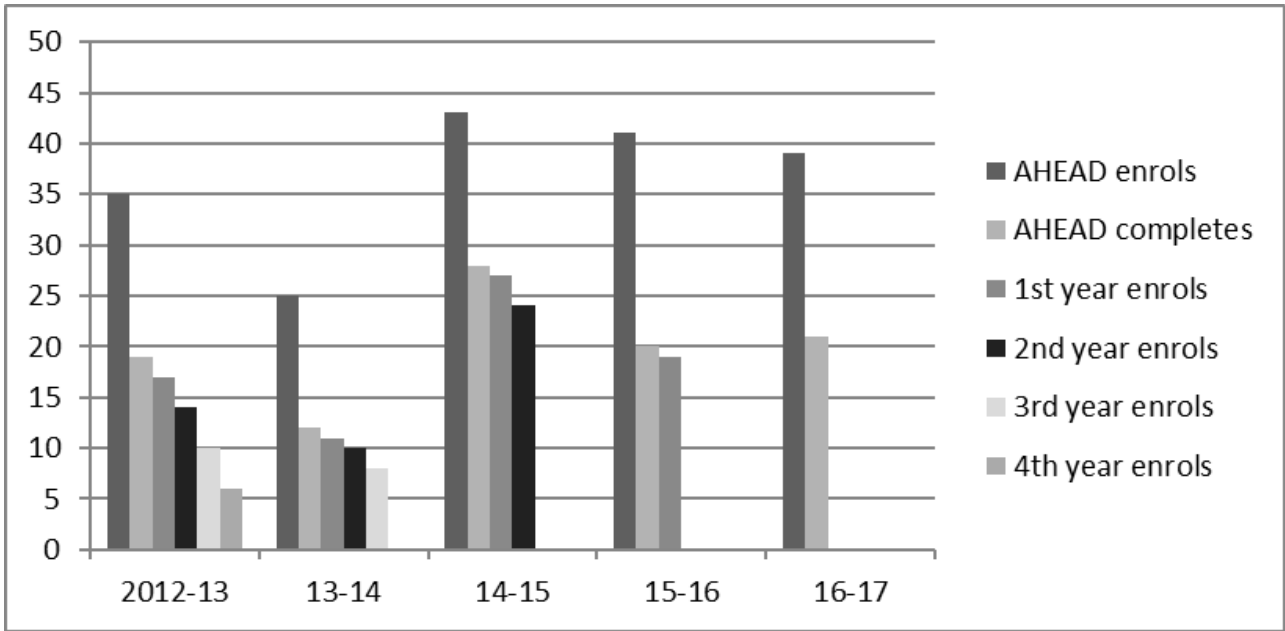

A comparison of attainment (Figure 2) revealed that there were no significant differences in overall degree outcome, but that former AHEAD students did significantly better in stages 2 and 3 of their university degree $(\mathrm{t} 9=2.25$ and $\mathrm{t} 6=7.74, \mathrm{p}<0.05)$ while achieving a significantly lower GPA at stage $1(\mathrm{t} 16=-19.5, \mathrm{p}<0.05)$ (though still attaining a $2: 2$ grade point average). This would suggest that more could be done to improve the first year of transition.

Figure 2: AHEAD Student Attainment using GPA as the Comparator 


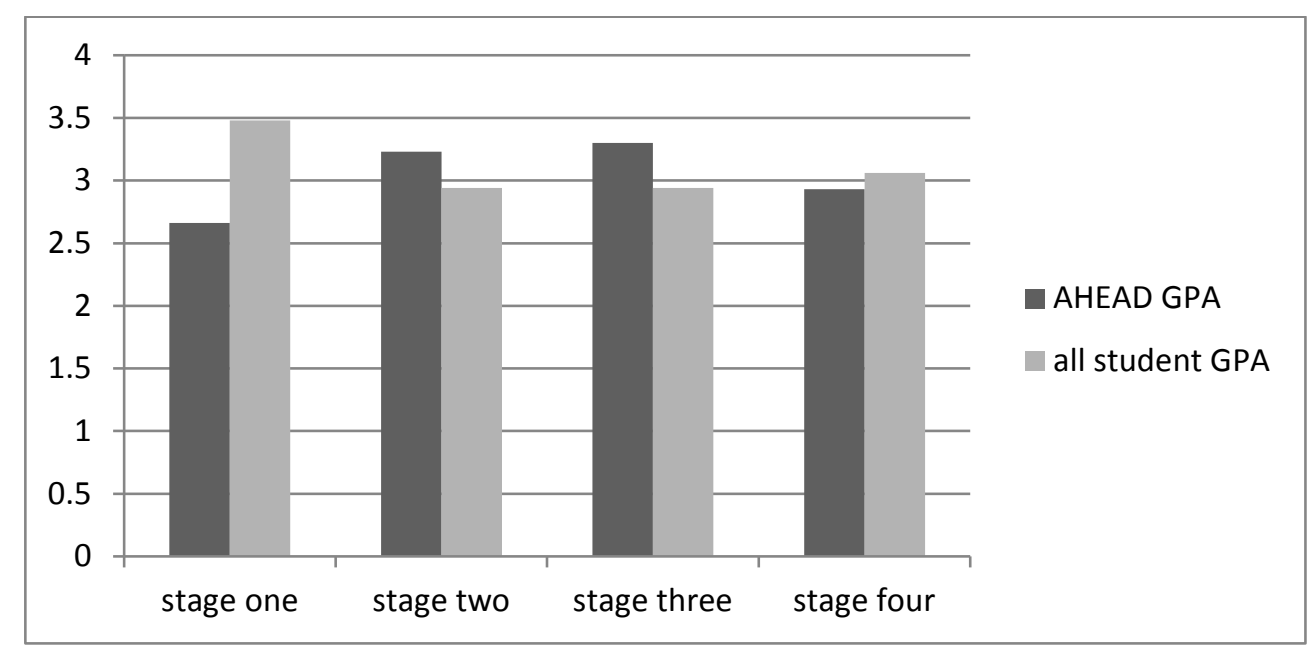

\section{Interview \& Focus Group Research Findings}

The AHEAD programme was widely articulated as a transformative experience, offering those who generally did not believe that university was for people like them, the opportunity to embark on a university career. The majority of participants viewed AHEAD very positively as it offered "such an opportunity to get into university" (Student $O$ ). As a free part-time evening programme, AHEAD was viewed as relatively risk-free enabling those in full-time employment or with caring responsibilities the opportunity to attend. As one student noted: "you weren't actually losing anything if you did drop out and you didn't pass it.” (Focus Group B)

The main strengths of the programme identified by participants included: building confidence; developing academic skills; providing strong academic support; facilitating a peer-support network that often lasted throughout their university career; as well as initiating them into university culture and its associated processes. What the programme did less well was support the initial transition into first year which, in part, explains students' below average performance in their 1st year of undergraduate study.

\section{Building Confidence}

AHEAD helps to demystify university for these students; breaking down the barriers between the university and the local community. While the AHEAD student population is drawn from a variety of backgrounds, it is predominantly local people from the Tayside region. Often this local population did not think that university was for them; in some cases, they were the first to go to university amongst their friends and family.

Many interviewees also questioned their academic ability before doing the AHEAD programme; but in most cases what was lacking was selfconfidence and a belief in their own ability to learn: 
"So you start the AHEAD course thinking 'No way can I do this' ... yeah, you finish it saying 'I can absolutely do this. I can do this"'. (Focus

Group B)

Negative experiences of schooling are not uncommon amongst AHEAD students. Such experiences tend to both undermine self-confidence and limit options for continuing their education. For example, one respondent simply stated, "I hated school" (Focus Group B); while another described their experience as "horrendous" (Student C). However, for others they were simply not interested in school at that time. Student A, for example, admitted going to "school because I wanted play football."

The regimented nature of schools could be a barrier itself, especially for those from chaotic family backgrounds. A few of our interviewees felt failed by schools and teachers who were not as supportive as they could have been. One interviewee was told to put out of their mind any ideas of going to university whereas another had been refused the opportunity to sit their foundation exam because of poor attendance. For this interviewee, the negative experience of school had undermined their self-confidence to such a degree that they were sure they were not 'clever enough' (Student V) to even be accepted on the AHEAD programme.

Even for those students who enjoyed school, sometimes circumstances forced them to make other choices. For example, one participant "had to stay at home and take care of ...siblings" (Focus Group B); whilst another was forced to leave home before completing school:

"I liked school and I had ambition, however I didn't have a good life at home and it made it difficult for me to be able to stay in that home and continue to go to school, so the only option I had was to leave home so I left on my 16th birthday, continued to go to school for 6 weeks, but that proved to be a lot more difficult and because I moved in with a friend and her mum needed me to pay board in order to be able to keep me, so I left school and got a job and I've been working ever since..." (Student D)

A recurrent theme amongst interviewees was how a disrupted education and a poor school experience led to lack of self-confidence and a perception that it had diminished their opportunities.

\section{Skills Development}

As a widening access programme designed to cater for a diverse group of individuals with a range of abilities and experiences, a primary focus of AHEAD is skill development. The first semester focuses on ensuring all students have a minimum skillset necessary for successfully completing the subject-based options in semester 2 . This diversity inevitably means that AHEAD starts at a fairly low level and quickly builds to the equivalent of level 6 in the Scottish Credit and Qualification Framework (SCFQ). The 
first semester is, therefore, about learning the basics, whereas semester 2 is more concerned with disciplinary knowledge aimed at easing the transition into their chosen degree subject. As Student D noted:

"I needed semester one to be able to go on to do semester two, because semester two assignments I would never have been able to write a 1500 word essay on ethnicity without semester one teaching me how to write an essay, how to reference, how to structure, I never really understood the whole intro, main body, conclusion... you don't come into University for the first time after school 15 years ago and know how to do that."

Another participant found that their assessment feedback in the first semester of the AHEAD programme continued to be useful even after they had transitioned into their undergraduate degree:

"I kept them next to me, and every time I was doing my essay I was referring back to my feedback..., it worked wonders, I have to say it did work wonders." (Focus Group B)

\section{Benefits of a doing University Based Access programme}

Our participants suggest that there are unique benefits associated with a university-based access programme, particularly those delivered by the university the students are planning to attend. While all students successfully completing the AHEAD programme were awarded 60 SCQF level 6 credits (equivalent to Highers); the programme was specifically designed to ease entry into an Abertay degree. This benefitted the student by familiarising them with the university, its systems, available support and its physical layout. For example, a number of participants believed that first year would have been more challenging without the orientation to the university offered by the AHEAD programme:

"I knew how to use the library, there was no stress at all to defining the rules or because it was not a new place for me, and I was more confident that I knew the university would require a lot of course work and as I already knew roughly how to do them I felt more confident about this area, yes so the transition was easier definitely compared if you just come first day, new university everything new, it would be a bit more stress." (Student O)

In this way, the AHEAD programme not only gave them the necessary skills but also "a head start" (Student E) as well as a means of developing a relationship with their fellow students on their course:

“... when I started in first year, like I already knew how to do all that, it was fine - you see all these new people coming in first year and they're total lost! And I was like 'I'll show you, don't worry'. So yeah, it was... it was good to know in advance a little bit about the uni and where 
everything was, where the classrooms and that were, so, yeah." (Student F)

Already being embedded in university systems and processes also allowed these students to focus more on their studies in their first year. AHEAD students are offered greater levels of support than those normally offered to undergraduate students and have specific training on how to use the university's facilities embedded into their programme classes. While there are regular workshops for all new undergraduates offered by different university services, they are normally voluntary and poorly attended.

\section{Improving AHEAD and Transition to Undergraduate Study}

While this study has been able to demonstrate both the value and benefits of the AHEAD programme as an entry route into higher education; the research also highlighted that there was an attainment gap in $1^{\text {st }}$ year (Figure 2 ) which would suggest that more support for transition was still required. A small number of criticisms and potential improvements were highlighted by our interviewees.

Some of these criticisms were associated with the need for AHEAD to cater for a diverse population with different skillsets and different degree aspirations. This translated into a number of comments concerning the pace, level and the content of the programme. For example, some found AHEAD too easy and would have preferred a quicker pace, particularly in the $1^{\text {st }}$ semester; whereas others found it very challenging and needed more support and time.

This divergence was most apparent in the teaching of mathematics; a topic that many found particularly challenging. For example, the key skills module in semester 1 initially had very little mathematics beyond foundation-level arithmetic. Students planning to apply for a science-based degree were expected to complete the Access to Science module in semester 2 , a joint mathematics and chemistry module. This structure created two major problems: (1) it forced students who needed little more than basic arithmetic skills, such as prospective mental health nursing students, to complete a module with a significantly higher level of mathematics than they required; and (2) it concentrated the teaching of mathematics into a short 6 week block in semester 2 which did not give those who struggled with mathematics sufficient time to master the subject. Both problems resulted in a higher failure rate for the Access to Science module.

Furthermore, compelling prospective mental health nursing students to take a module that was largely superfluous to their future career and education needs was an unnecessary barrier to higher education in itself. Our solution was to increase the basic mathematics teaching in the first 
semester to provide these students with the level of mathematics they required for their course without requiring them to complete the Access to Science module in the second semester. As these students would be required to complete drug calculations with $100 \%$ accuracy, a special session on drug calculations was also included in the first semester key skills module specifically for students wishing to apply for a nursing degree.

A further advantage to increasing the amount of basic mathematics taught in the first semester was that it created space in semester 2 for more advanced material to be taught as part of the Access to Science module, ensuring students taking this module had a better grounding. Subsequently, the module was also redesigned to increase the proportion of mathematics from half to two thirds of the module's content. While, within the timeframe of this study it was too early to fully assess the impact of these changes, in 2017-18 all students undertaking the Access to Science module passed at the main diet.

Concerns were also raised about the extent to which AHEAD students were made to feel part of the university. While this may partly be related to their feelings of inadequacy and low self-esteem, such feelings were accentuated by their perception that some staff were not committed to this programme. For example, specific concerns were raised about one member of staff who they felt did not to see the merit of, and was not interested in teaching, an access module. As one of a number of students stated: "the guy didn't want to be there". (Focus group A)

Unfortunately, this negative attitude towards AHEAD students followed them into their undergraduate degrees. For example, one former AHEAD student recounted a conversation where a lecturer exclaimed:

'I can't believe you guys were even allowed to do this course because this is ridiculously hard for somebody that's just come off the AHEAD course... that made me feel a bit like 'Oh god!' (Focus Group B)

While such accounts were very rare, it underlined the need to educate lecturers in the University about the mission and content of the AHEAD programme. It was also important to make staff aware that each faculty supported the delivery of the subject specific content in the second semester. Incidents such as these resulted in a strong statement of support from the University's Executive Group with Deans being tasked with ensuring that their staff understood and supported the programme.

A final area of concern was the sense of abandonment AHEAD students felt at the end of their course. While students were supported in making their degree choice and helped to complete the direct entry application form; the programme team recognised that more information and general support was required to aid transition. This was particularly important as many AHEAD students were the first in their family to go to university and therefore had no one outside the university to offer reassurance and advice: 
"It's just... I don't know, none of my like family have been to uni before that, everyone else just went from school straight into full time work they entered the Forces mainly. So I was like doing something new, I didn't really have anyone, like any close friends or family that had done it. So I didn't have anyone I could ask..." (Student F)

Many of the AHEAD students were also giving up full time work to become an undergraduate student and were understandably concerned about the financial implications of doing a degree. Most of these students also had children and significant household costs which can be less of a concern for those students entering university directly from high school. For example, one single parent had no idea about the Scottish Awards Agency for Scotland (SAAS) or other financial support that was available to her:

“... as a single parent in my thirties, the only thing I would have said would have been good is if we had had some level of information regarding the other side of study, so not the academic but the things like funding, I never knew what SAAS until someone piped up in the class to say, by the way what's SAAS and what do we do and I went, well that's who pays your tuition fees, you know if you apply, well how do you apply, you know if we had a little, even one or two sessions that taught you about SAAS, about bursaries, child care, discretionary funds, things like, the other side of it because I sat there and at times I thought this is going so well but let's face it I don't even know if I can afford to come back and do the degree..." (Student D)

Supporting transition for these students can be a process of alleviating their fear of the unknown. For example, another widely raised concern was the fear that everyone else in their class will be much younger and that "they're just gonna ignore me, I'm this old fart ... it's gonna be horrendous"' (Student K).

Other concerns relate to how they can fit full-time study into their already busy lives. One focus group participant recounted reacting to her timetable, saying:

'I can't do that', crying... just crying ... I'm like... 'I can't fit that in' and

'I can't go to work and who's gonna pick the kids up?' Who's gonna do what... how is it gonna fit in?" (Focus Group A)

In this case the student had a supportive partner and was able to speak to her employer and reduce her hours. However, her experience and that of other students stressed the need for a supportive preparation process. This resulted in a number of changes being actioned for the 2017-18 session. For example, the programme team:

- Sought to ensure better alignment of AHEAD subject options and first year undergraduate programme content to better prepare students for undergraduate study. 
- Arrange an end of course meeting to facilitate a successful transition to $\mathrm{HE}$, for example, providing information on applying to SAAS, the registration process and timetables.

- Having an end of course celebration and giving successful students AHEAD graduation certificates.

- Strengthening the relationship with student support services in order to ensure the early identification of extra support needs of AHEAD students.

- Having a dedicated academic staff member to support AHEAD students with any academic issues during their 1st year in order to support retention.

While, it is too early to assess the impact of these actions, the performance of the 21 who made the transition to undergraduate study in 2017-18 has been very positive with only one student withdrawing and another suspending. The average GPA of the 2016-17 cohort in their first year of undergraduate study was 3.28, equivalent to a 2-1 grade.

Furthermore, the performance of the 2017-18 AHEAD students has also shown a minor improvement on 2016-17 with 55.36\% of new starts successfully completing the programme and, of the 28 students who submitted their key skills portfolio in term $1,75 \%$ successfully completed the programme.

\section{Discussion}

The role of higher education in enabling transformational learning and access to alternate opportunities is well documented (Kasworm \& Bowles, 2012); a finding that is clearly echoed by our former AHEAD students. However, as higher education aligns more closely with middle-class values, those non-traditional students from working class and ethnic minority backgrounds, particularly those who are first generation university students, can find the culture of university challenging (Christie, Munro \& Wager 2005; Marshall 2016; Ulriksen, Madsen, Holmegaard, 2017). While many of these students may feel more comfortable in a new university setting (Read, Archer and Leathwood 2003), their discomfort with the higher education environment is reflected in the qualitative commentary which gives voice to feelings of insecurity, isolation and exclusion. AHEAD students are not alone, as the experience of identity 'crises' are widespread and reflect the increasing diversification of the Scottish higher education sector (Crossan, Field, Gallagher and Merrill 2003; O'Donnell and Tobbell, 2007; Furlong and Cartmel 2009).

Learners' identity has been recognised as important for transition, particularly for those from a non-traditional background. Successful transition into higher education requires the student to develop a student identity as well as "learn(ing) to act autonomously as a university student" 
(Briggs, Clark and Hall 2012: 6). While this does not mean adopting the middle-class student habitus of the 'traditional' university student (see Christie, Munro \& Wager 2005), it does require an identity which accommodates university. This study suggests that some AHEAD students struggle in constructing a University student identity. However, the AHEAD programme attempts to foster this by encouraging students to reflect upon their learner journey and to consider the cultural, social and structural reasons for the educational choices they have made in their lives. Their first essay assignment, for example, seeks to develop a sociological imagination (Mills 1977) whereby they can see how their individual biography intersects with the structural realities of the place they inhabit. While former AHEAD students may still see themselves as different from the school leavers on their programmes, it gives them the confidence to embrace this difference and to find their own place in the culture of the university.

Within the literature there has been a limited discussion of the extent to which traditional college-based access programmes adequately prepare widening access students for the culture of higher education (Walker 2000; Leech, Marshall and Wren 2016; Gallacher 2017). Widening Access in Scotland has typically been delivered through college sub-degree level courses which have articulation routes into degree level studies (Weedon 2015). However, while colleges are very good at widening participation, a potential downside is that they may unwittingly divert students to less prestigious courses and institutions (Gallacher 2017). Furthermore, their emphasis on more practical skill development may not adequately prepare these articulating students for the academic and assessment demands of a university degree, resulting in higher drop-out rates (Blackburn et al 2016). While there is little doubt that further education-based access programmes are an essential part of the widening access landscape, particularly in the way in which they address themselves to the prospective students' skillset, the extent to which such courses can support a university student identity is less clear. Wingate (2007) argues that to effectively support transition, educators need to go beyond a skills-based approach. Such approaches, Wingate argues, are based on the 'deficiency model'; while they address the perceived skills gaps of individual students, arguably such approaches do not prepare them for learning in a university setting. As was clear from the interviews and focus groups with former AHEAD students, a key benefit of a university-based access course is that it supports transition by embedding these students in the culture of higher education institutions which better prepares them for doing a university degree. While Wingate's study specifically focused on supporting students making the transition from high school to first year university, the experience of widening access students would also confirm her conclusion that successful transition relies on the ability of these students to become independent university learners in their chosen discipline. 
Research also suggests that the mismatch between the expectations of, and the actual reality of, undergraduate study at university, may lead to adjustment difficulties in first year (Briggs, Clark and Hall 2012). While this study suggests that former AHEAD students are not immune to such difficulties, the programme does provide its students with a good understanding of what university will be like. The AHEAD programme was consciously designed in two parts: the first sought to address any skill development needs in the first semester; while the second semester was designed to mimic the first year undergraduate experience both in terms of teaching format and assessments. In this way the AHEAD programme is specifically focused on constructing the autonomous university student and embedding that student into the culture and support networks of the university. This approach may help to explain the success of a universitybased access programme, such as AHEAD, in conferring an advantage over those courses offered by college partners, which arguably socialise students into college not university culture.

Surprisingly, given the emphasis of the Scottish Government on widening participation, there have been relatively few academic studies exploring the success of Access to HE students in their undergraduate degrees. Osborne, Leopold and Ferrie (1997) concluded that the relative success of access students was dependent on the access route and the level of control the university exercised over that route; students from the SWAP programmes performed less well and they concluded that the HE and FE sector must work more closely together to ensure that access students are fully prepared for university. Another early analysis that explored SWAP students' performance at Glasgow University (Walker 2000) found that SWAP students who attended Glasgow University's Pre-University Summer School performed better in their undergraduate degrees than those who went straight from the SWAP programme into first year, even though dropout rates in first year were comparable. Both these early studies would suggest that access students benefit from university engagement prior to undertaking their undergraduate degree.

Another study which focused specifically on successful access students at two pre-1992 Scottish universities (Christie, Munro and Wager 2005) found that many non-traditional students construct themselves as different from the traditional middle-class student that typically inhabits these institutions. Such students rejected the lifestyle of the typical 'irresponsible' 18-year-old and tended to have a more instrumental approach to university study, keeping their student and home lives separate. While new universities may have a more diverse student population, these findings certainly echo some of the AHEAD interview statements which viewed university as means to an end and as an opportunity to better the student and their family's socio-economic position, not as a place to socialise and become an adult. What this might 
suggest is that to some degree, non-traditional students need to consider how to accommodate and situate university in their lives. A university-based access programme like AHEAD, while it cannot give them that middle class habitus, can and does offer them the space to come to terms with becoming a university student.

\section{Conclusion}

Successive governments have demanded that universities widen access to increase the proportion of students from disadvantaged and BME communities. This has resulted in a variety of initiatives including school outreach programmes, taster sessions, summer schools and the use of contextual offers to both promote applications to university from these groups and recognise the additional barriers that may result in these students performing less well. For those without the requisite qualifications Access to Higher Education Diplomas offered by colleges, Foundation Degrees and, in Scotland, the college-based SWAP programme offer alternative entry routes into higher education. Many of these programmes are full-time courses and do not provide prospective students who are in full-time work the opportunity to obtain the qualifications they need to go to university. A few universities, however, now offer free part-time evening Access to Higher Education programmes such as AHEAD.

The literature on students accessing higher education through non-standard routes would seem to suggest that students benefit from pre-entry engagement with their chosen university. Our study would seem to confirm that many students do benefit from what amounts to a year-long induction to their university degree. Former AHEAD students discussed the way in which the programme not only strengthened their skillset but also increased their confidence, familiarised them with university systems and expectations and perhaps most importantly of all helped them to develop their identity as a university student. The fact that former AHEAD students perform equally as well as the average Abertay student would suggest that the programme has been a successful alternative route to higher education.

While a diversity of widening access options are required to meet the needs of widening access students, the experience of the AHEAD programme would suggest that other university's should consider developing a university-based access programme as this may provide, for some students, the most direct route to developing the confidence, skills and identity necessary for successfully returning to education. 


\section{References}

Annetts, J., Cameron, A., Work, H., Miller, A., Niitamo, V., Stirling, M. (2017) 'Attainment and transition experiences of students progressing from an evening access programme to undergraduate study', Paper presented at SRHE Annual Research Conference, Newport, United Kingdom.

Bourdieu, P. (2010) Distinction, London: Routledge.

Bowl, M. (2001) 'Experiencing the Barriers: Non- Traditional Students in Higher Education', Research Papers in Education, 16, 2: 141-160.

Blackburn, L. H., Kadar-Satat, G., Riddell, S. \& Weedon, E. (2016) Access in Scotland: Access to Higher Education for People from Less Advantaged Backgrounds in Scotland, London: Sutton Trust.

Briggs, A., Clark, J. \& Hall, I. (2012) 'Building Bridges: Understanding Student Transition to University', Quality in Higher Education, 18, 1: 3-21.

Christie, H., Munro, M., \& Wager, F. (2005) 'Day Students' in Higher Education: Widening Access Students and Successful Transition to University Life', International Studies in Sociology of Education, 15, 1: 3-29.

Crossan, B., Field, J., Gallacher, J., and Merrill, B. (2003) 'Understanding participation in learning for non-traditional adult learners: learning careers and the construction of learning identities', British Journal of Sociology of Education, 24, 1:55-67

Department for Business, Innovation \& Skills (BIS) (2014) National Strategy for Access and Student Success in Higher Education, London: HMSO.

Dundee City Council (DCC) (2015) About Dundee, Dundee Partnership. KL/8/15 Retrieved from http://www.dundeepartnership.co.uk/sites/default/files/About\%20Dundee\%202015.pdf

Furlong, A. and Cartmel, F. (2009) Higher Education and Social Justice Buckingham, SRHE and Open University Press.

Gallacher, J. (2017) 'Higher education in the college sector: widening access or diversion? Questions and challenges from the Scottish experience', Journal of Education and Work, 30, 7: 712-721.

Kasworm, C. E., \& Bowles, T. A. (2012). 'Transformative learning in the workplace: Leading learning for self and organizational change' in E. W. Taylor \& P. Cranton (Eds.), The handbook of transformative learning: Theory, research, and practice, San Francisco, CA: Jossey-Bass.

Leese, M. (2010) 'Bridging the Gap: Supporting Student Transition into Higher Education', Journal of Further \& Higher Education 34, 2: 239-251.

Leech, S., Marshall, C. A., and Wren, G. (2016) 'Understanding Foundation Year Provision' in C. A. Marshall, S. J. Nolan, D. P. Newton (eds.) Widening Participation, Higher Education and Nontraditional Students, London: Palgrave Macmillan.

Marshall, C. A. (2016) ' Barriers to Accessing Higher Education' in C. A. Marshall, S. J. Nolan, D. P. Newton (eds.) Widening Participation, Higher Education and Non-traditional Students, London: Palgrave Macmillan.

Mills, C. W. (1977) The Sociological Imagination, Oxford: Oxford University Press.

O'Donnell, V.L. \& Tobbell, J. (2007). 'The Transition of Adult Students to Higher Education: Legitimate Peripheral Participation in a Community of Practice?' Adult Education Quarterly 57, 4:

Retrieved from http://journals.sagepub.com/doi/pdf/10.1177/0741713607302686

Osborne, M., Leopold, J. and Ferrie, A. (1997) 'Does Access Work: The relative Performance of Access Students at a Scottish University', Higher Education 33: 155-176. 
Read, B., Archer, L. \& Leathwood, C. (2003) 'Challenging Cultures? Student Conceptions of 'Belonging' and 'Isolation' at a Post-1992 University', Studies in Higher Education, 28, 3: 261277.

Scottish Government (2015) Commission on Widening Access: Interim Report, Edinburgh: Scottish Government.

Ulriksen, U., Madsen, L.M. \& Holmegaard, H.T. (2017) 'The first-year experience of non-traditional students in Danish science and engineering university programme' European Educational Research Journal, 16, 1: 45-61

Walker, L. (2000) 'Predicting or Guessing: The Progress of Scottish Wider Access Programme (SWAP) Students at the University of Glasgow', International Journal of Lifelong Learning, 19, 4:342-356.

Weedon, E. (2015). 'Widening Access to Higher Education in Scotland, England and Europe' in S. Riddell, E. Weedon \& S. Minty (eds.) Higher Education in Scotland and the UK: Diverging or Converging System, Edinburgh: Edinburgh University Press.

Wingate, U. (2007) 'A Framework for Transition: Supporting 'Learning to Learn' in Higher Education', Higher Education Quarterly, 61, 3:391-405 